\title{
Prospects for Biofuel Industry in Fiji; Engine Performance of CNO blended Biodiesel
}

\author{
Krishnam Nair ${ }^{1, *}$, Rishal Amar Singh ${ }^{2}$ \\ ${ }^{1}$ College of Foundation Studies, University of the South Pacific, Suva, Fiji \\ ${ }^{2}$ College of Engineering, Science and Technology, Fiji National University, Suva, Fiji \\ *Corresponding author: nair_k@usp.ac.fj
}

Received September 11, 2014; Revised December 14, 2014; Accepted December 23, 2014

\begin{abstract}
Vegetable oils and their spinoff biofuels, unremarkably named as "biodiesel," are prominent candidates as alternative diesel fuels. Twelve different blends of CNO, Ethanol and Butanol hybrid biofuel were tested for engine efficiency and it is discovered that they are technically competitive with or provide technical benefits compared to conventional diesel fuel. Besides being a renewable and domestic resource, biodiesel reduces most emissions while engine performance and fuel economy are nearly identical compared to conventional fuels. A comprehensive study of Fiji's coconut industry is also undertaken.
\end{abstract}

Keywords: Biodiesel, Biofuel, CNO, Ethanol, Butanol

Cite This Article: Krishnam Nair, and Rishal Amar Singh, "Prospects for Biofuel Industry in Fiji; Engine Performance of CNO blended Biodiesel." American Journal of Energy Research, vol. 2, no. 4 (2014): 99-104. doi: 10.12691/ajer-2-4-4.

\section{Introduction}

Depletion of the world's fossil fuels and the high global demand in energy has led to a relentless increase in fuel prices. Higher fuel prices have led to higher transport and power costs, which, in turn have a multiplied negative effect on the prices of goods and services. One way of offsetting this inclination is by gradually shifting dependency on fossil fuel, which is in dwindling supply and at the mercy of global politics, with renewable energy sources such as wind, tidal and solar energy, and with biofuels. The replacement of fossil fuels with renewable sources such as biofuel also benefits the environment since it helps to reduce noxious emissions and the global warming effect of man- made $\mathrm{CO}_{2}$ emissions. Security of fuel supply, fuel costs and the effect on the environment have become key issues that have spurred countries like Fiji and the other nations in the South Pacific.

In Rudolph Diesel's 1893 paper "The Theory and Construction of a Rational Heat Engine", the German inventor described a revolutionary engine in which air would be compressed by a piston to a very high pressure thereby causing a sufficiently high temperature to ignite non-volatile oils (that is, to achieve compression ignition, CI, rather than spark ignition, SI). His first working engine could run on various vegetable oils, leading him to envision in 1911 that "the diesel engine can be fed with vegetable oils and will help considerably in the development of the agriculture of the countries that use it”.

Owing to their high viscosities, the injection, performance, combustion and atomization characteristics of vegetable oils in both direct injection and indirect injection diesel engines are however, significantly different from those of petroleum derived diesel fuels. Having high viscosity, in long-term operation, vegetable oils will normally produce gumming, the formation of injector deposits, ring sticking and incompatibility with conventional lubricating oils [1].

Various types of hybrid fuels can be used in place of diesel or the conventional vegetable oil without any modification to the engine. These hybrid fuels comprise of $[2,3]$.

- Diesel, water, alcohol and surfactants.

- Diesel, vegetable oil, water, alcohol and surfactant surfactants.

- Diesel, fatty acids, water, alcohol and surfactants.

- Vegetable oil, water, alcohol and surfactant.

Alcohol is primarily blended for reducing the viscosity of the oil to ensure easy engine running and to avoid part wear and tear. Water is optional and used for formation of the hybrid fuel through aqueous alcohol. Singh, P (2007) [4] discovered that only $8 \%$ of alcohol could be blended with CNO for the blend to be miscible. This however, is not sufficient to proficiently lower the viscosity of the fuel. Surfactants are added. Surfactants are wetting agents that lower the surface tension of a liquid [5], allowing easier spreading, and lower the interfacial tension between two liquids thus ensuring miscibility between the alcohol and the vegetable oil.

Of the four types of hybrid fuels, the vegetable oilwater-alcohol-surfactant combination is studied. The vegetable oil in study was chosen to be CNO, since it abundant in supply in the region and fuel security would not be a hurdle. Aqueous ethanol was used (95; 5 alcohol, water ratio). Ethanol is appropriate for mixed fuels used in the diesel engine because of its high octane number, but 
its low cetane number and its high heat of vaporization resists self-ignition in the diesel engine [6]. Some surfactants are known to be toxic to animals, ecosystems and humans, and can increase the diffusion of other environmental contaminants [6]. Hence, two isomers of Butanol is used and studied. Butanol is produced from biomass, it tolerates water contamination, it is less corrosive than ethanol so handling and transportation is easier. Its longer hydrocarbon chain causes it to be fairly non-polar , thus is relatively environmentally friendly.

Apart from preparing and revealing engine performance of CNO based hybrid biofuels, this paper also aims to highlight the current status of Fiji's copra industry and its ability to supply and cater for the nation's energy needs.

\section{Coconut Industry in the Region}

Copra from coconuts is a major agricultural crop in the Pacific region. It was once an important export for Fiji. Fiji produces around 280 million coconuts every year, of which only 50 million are used for coconut oil production. The data estimates a far lower figure at 140 million but it is believe that the actual production to be over 280 million, The coconuts are mostly being consumed fresh with some fed to pigs. The imputed minimum value to coconut production is $\$ 15$ million [7]. In Fiji biofuels are divided into 2 sections as follows:

1. Government funded programs

Fuel type: Renewable diesel

Capacity per mill: 463,000 L

No. of mills: 1 (Koro Island), (1 Rotuma), (1Cicia)

2. Private sector programs

Niu Industries

Fuel type: Renewable diesel

Capacity per mill: 575,000 L

Biodiesel Group Company Limited

Fuel type: Biodiesel (transesterified)

Capacity: 144,000 L

Biofuels International (yet to begin biodiesel production) Fuel type: Pongamia biodiesel

Capacity: 4.8 Million L but this grows as the plants mature and yield increases

The demand for this crop from Pacific Island countries has fallen markedly, thus affecting revenue earned through export and forcing countries to venture into other industries to survive. Since it is indigenous, abundant in supply, and with a perfect climate for production, this crop has been explored widely as a biofuel in the region. A survey carried out by Pacific Islands Applied Geoscience Commission (SOPAC) has studied the potential of domestic coconut oil as a source of renewable energy. It confirms that a "large potential exists".

Raw materials for biodiesel production need to be selected according to their availability and cost in the country or region. Solomon Islands, Papua New Guinea and Vanuatu have successfully sustained their coconut industries and hence have found a way to commercialize its derivate biofuel. In Vanuatu, "Island Fuel 80" is retailed at US\$0.30 the Solomon Islands have taken initiatives to implement it in their countries. Blends of coconut oil with diesel have been tested on government vehicles in Kiribati, while coconut oil has been used unsuccessfully as fuel in diesel engines in the Marshal Islands.

Locally, copra is today processed into CNO within Fiji, at mills in Savusavu (Vanua Levu) and Lautoka (Viti Levu). CNO is consumed locally as cooking oil, used as a cosmetic in oil form, used as a raw material in soap making and sold for export.

However, the industry is facing difficult times and is facing hardships in supplying the nation's needs, and coconut oil in these days imported from abroad.

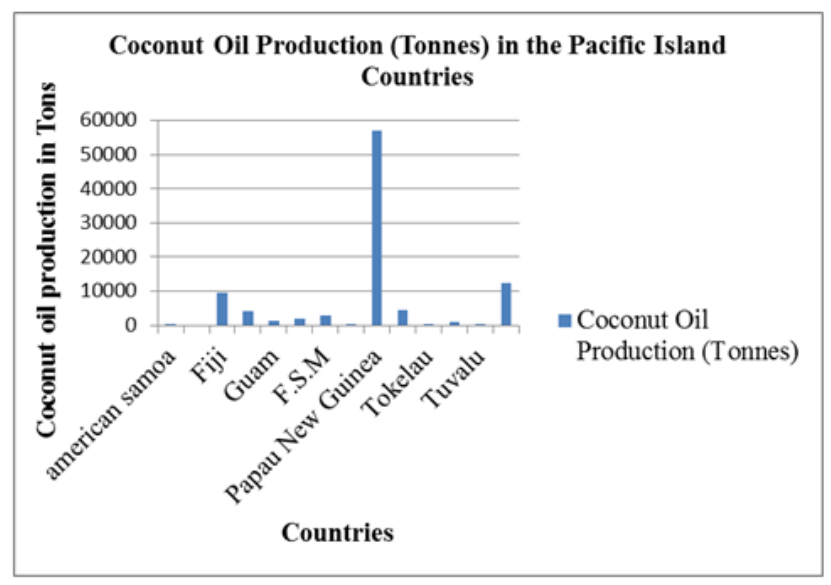

Figure 1. Coconut oil production in the Pacific Islands

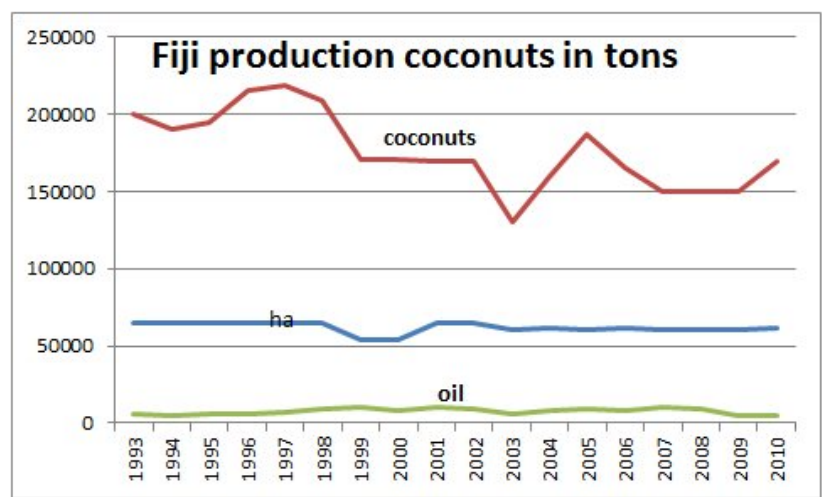

Figure 2. Fiji's Yearly CNO Production

The industry has been on the decline since 1950. In 2007 17,000 tonnes of copra was produced, which was only a third of what was produced 30 years ago (1977). See (Figure 6). Today, some of the major problems faced by the copra industry have been caused by decreasing production of coconuts resulting from cyclones, increasing numbers of senile trees and little planting of new trees, the relatively high price of coconuts (green and dried) in the local markets, rising freight costs (especially from isolated plantations), lucrative substitute crops and escalating land values of coastal lands.

The other constraints are coconut diseases and pest infestations (e.g. coconut crabs and rhinoceros beetles), the land tenure system (where a family's land resources are divided into small holdings), and recently labour shortages.

Another important issue worth attention is relating to sharing of proceeds between millers and planters. The proceeds are shared in the ratio of 30 and 70 per cent between the millers and the producers respectively for the first $\$ 400$. Any amount above $\$ 400$ is shared in the ratio 
of 25 and 75 per cent amongst the millers and the producers respectively.

On average, the millers receive 30 per cent of the proceeds while the remaining 70 per cent is distributed to the producers. Of the 70 per cent paid out to the producers, the actual mill gate price turns out to be about 67 per cent.

The balance is held in abeyance to support the copra stabilisation scheme. Since February 2003, the support price of $\$ 500$ was set by the Coconut Industry Development Authority (CIDA). The establishment of the stabilisation scheme and grading of copra for European markets was initiated by Lord Silsoe in 1963. These measures have to some degree assisted the industry which unlike the sugar industry is deprived of foreign assistance.

CIDA, however aim to revitalize and develop the coconut industry in Fiji for economic growth. It aims to plant 6 million trees on Vanua Levu, Tavueni and on other maritime Islands on the Northern division by the end of 2020.

Recent energy-resource studies in Fiji have expanded the information on coconut oil as biofuel. A joint initiative by Fiji Government, Department of Energy and SOPAC has calculated that the total energy available from local coconuts is sufficient to cater for the energy need of rural villages in Taveuni and Vanua Balavu [8]. However, for the industry to provide the energy needs of whole of Fiji, massive scales of farming and cultivation must be done. This extent of agriculture is not feasible, even for Fiji, and thus the Energy department and CIDA are only endeavouring to provide energy needs from CNO to islands and villages which have abundant coconut trees but a limited load demand. Examples of such energy recipients include Vanuabalavu and Welagi which have had $80 \mathrm{kVA}$ and 45kVA generators installed respectively. It was discovered that 10 nuts gave an energy amount equivalent to 1 litre of diesel [8].

\section{Methodology}

\subsection{Preparing Blends}

Using Singh's (2007) [4] discovery of threshold CNOethanol ratio for miscibility being $8 \%$ ethanol (by volume), blends with more than $8 \%$ ethanol was chosen. The surfactant volume was chosen arbitrarily but always kept in lesser or same amount as ethanol. To ensure safe fuel volatility and that the fuel is CNO based, the volume of CNO was kept more than $50 \%$ of the blended fuel.

Table 1. Composition of blends using Butan-1-ol/Butan-2-ol as surfactants

\begin{tabular}{|c|c|c|c|}
\hline Designated code & \multicolumn{3}{|c|}{ Composition (\% vol) } \\
\hline & Crude CNO & Ethanol & Butan-1-ol / Butan-2-ol \\
\hline HF 1/7 & 87 & 10 & 3 \\
\hline HF 2/8 & 70 & 17 & 13 \\
\hline HF 3/9 & 54 & 23 & 23 \\
\hline HF 4/10 & 85 & 10 & 5 \\
\hline HF 5/11 & 67 & 17 & 16 \\
\hline HF 6/12 & 53 & 23 & 24 \\
\hline
\end{tabular}

\subsection{Procedure for Determining Gross Calorific Value/Energy Content}

The Energy contents of the different blends were obtained using a Ballistic Bomb Calorimeter. The sample is ignited by sending a small electrical current through a wire that ignites the fuel sample. A thermocouple senses the increase in temperature from the combusting sample, which is measured by a sensitive galvanometer.

To standardize the apparatus, a correction for constant heat gain and calibrating with a standard sample was performed. This test was carried out in the standard manner using benzoic acid whose calorific value is 26.44 $\mathrm{kJ} / \mathrm{g}$.

The sample and the crucible were placed in the support pillar with a $5 \mathrm{~cm}$ length of cotton thread. One end of the thread was tied to the firing wire and the other end was gently placed amongst the blended fuel inside the crucible. The fire button initiated the combustion process and the amount of heat released was indicated by the deflection of the galvanometer. In order to achieve precision, three tests were done using each fuel blend.

\subsection{Determining the Engine Efficiency}

The two general types of diesel engines are the direct injection (DI) engine and the indirect injection (IDI) engine. In DI engines, the fuel is directly injected into the combustion chamber in the cylinder. In IDI engines, the fuel is injected into a prechamber which is connected with the cylinder through a narrow passage [9]. The generator that was utilized had a Direct Injection engine.

The Generator specifications are given below;

Gen. Type - Brushless, 2-poles, single phase

Max. AC output - 3.5 kVA

Rated AC output - 2.8 / 3.3 kVA

Rated AC voltage $-240 \mathrm{~V}$

Frequency $-50 \mathrm{~Hz}$

Engine Type - 2 stroke, diesel engine

Before each trial of Hybrid fuel, the engine was run first on diesel for 5 minutes and then let to run on the 100 $\mathrm{mL}$ of the hybrid fuel tested. This was done to flush out any previous mixtures that may have still being in the fuel injection system [10].

As a preliminary, the energy loss of the system was calculated by letting the system run without a load and measuring the time for $100 \mathrm{ml}$ of the test fuel to be consumed. Data was collected for $0 \%, 30 \%, 55 \%$, and $85 \%$ of the maximum load of generator.

Normally a dynamometer is used in the determination of engine efficiency. However this was not available so the following method was considered.

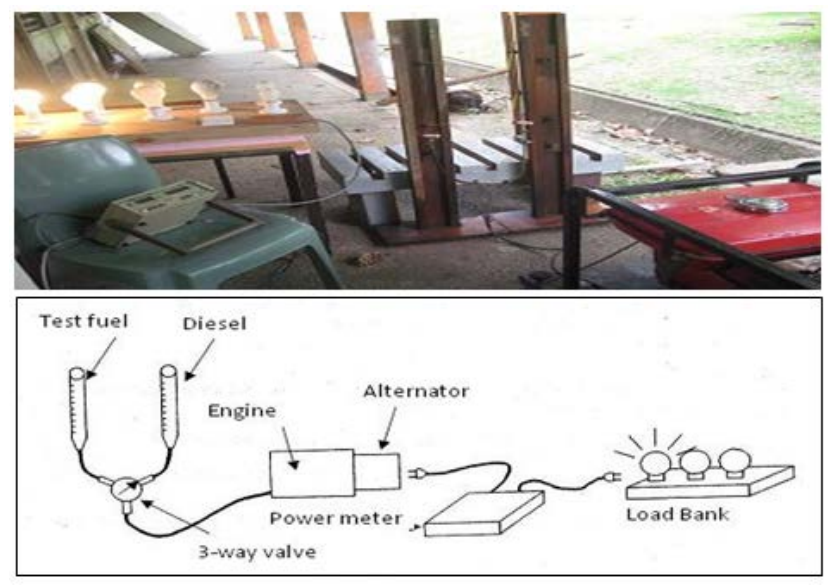

Figure 3. Schematic and pictorial of efficiency testing setup 
The efficiency of the generator engine is determined by the quotient of the system efficiency $\eta_{s}$ and the alternator efficiency $\eta \mathrm{A}$. The alternator efficiency is pre-specified in the manufacture's specification and was found to be $68 \%$. This efficiency was assumed to be constant for any load or fuel intake. The system efficiency $D_{\mathrm{s}}$ however needed to be calculated.

$$
\begin{aligned}
\eta_{s} & =E_{\text {out }} / E_{\text {in }} \\
& =\frac{P_{\text {out }} \times 1000 \times 100 \%}{G C V \times V_{\text {used }}}
\end{aligned}
$$

Where $\mathrm{P}_{\text {out }}$ is the power output of the generator (watts), $\mathrm{t}$ is the time for the specified volume $(100 \mathrm{ml})$ to be consumed, GCV is the gross calorific value of fuel $\left(\mathrm{kg} \mathrm{ml}^{-}\right.$ ${ }^{1}$ ) and $V_{\text {used }}$ is the volume of fuel consumed per test run.

\section{Results and Discussion}

Ethanol and the studied surfactants added to crude CNO was not miscible immediately after blending. A visible layer formed. A homogenous mixture was obtained after 12 hours of waiting time. This trend was same for both isomers of butanol.
A

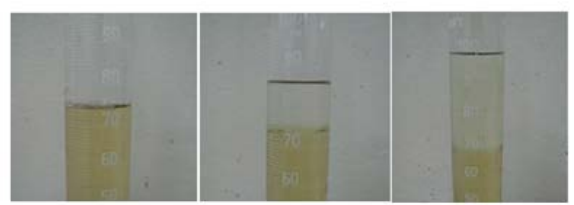

$\mathrm{D}$

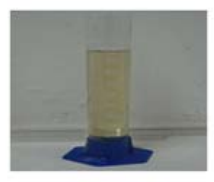

Figure 4. (A); crude CNO, (B); layer formation after ethanol being added, (C); layer after butanol being added (D); resultant homogenous mixture post 12 hours of blending.

An important property of any fuel is its density. The density gives hindsight into the type of handling and transportation cost it may incur also reveals some insight into the arrangement of the molecular structures.

\begin{tabular}{|c|c|c|}
\hline Test Fuel & Density (g/ l) & Error (\%) \\
\hline Diesel & 0.82 & 0.4 \\
\hline Crude CNO & 0.93 & 0.5 \\
\hline HF1 & 0.92 & 0.4 \\
\hline HF2 & 0.88 & 0.3 \\
\hline HF3 & 0.82 & 0.6 \\
\hline HF4 & 0.87 & 0.4 \\
\hline HF5 & 0.85 & 0.3 \\
\hline HF6 & 0.86 & 0.4 \\
\hline HF7 & 0.90 & 0.5 \\
\hline HF8 & 0.87 & 0.3 \\
\hline HF9 & 0.81 & 0.3 \\
\hline HF10 & 0.79 & 0.4 \\
\hline HF11 & 0.82 & 0.3 \\
\hline HF12 & 0.87 & 0.4 \\
\hline
\end{tabular}

Table 2. Density of Fuels

It is noted that fuels with a greater CNO base are denser. This is comprehensible since crude CNO is relatively denser than the other two constituents.

(Table 3 ) lists the GCV based on mass basis and volume basis of diesel, crude CNO and the hybrid fuels prepared. Fuels containing Butan-1-ol as the mixing agent seem to have more energy per grams than ones containing Buatn-2-ol. The measured GCVs are also used in efficiency calculation.
Table 3. Gross Calorific Value of Fuels

\begin{tabular}{|c|c|c|}
\hline Test Fuel & GCV $(\mathrm{kJ} / \mathrm{g})$ & GCV $(\mathrm{kJ} / \mathrm{mL})$ \\
\hline & & $37.8 \pm 0.4$ \\
\hline Diesel & $45.1 \pm 0.8$ & $34.8 \pm 0.6$ \\
\hline Crude CNO & $39.4 \pm 0.6$ & $33.0 \pm 0.4$ \\
\hline HF1 & $34.6 \pm 0.5$ & $32.1 \pm 0.5$ \\
\hline HF2 & $35.9 \pm 0.6$ & $30.7 \pm 0.5$ \\
\hline HF3 & $35.0 \pm 0.4$ & $33.4 \pm 0.6$ \\
\hline HF4 & $36.6 \pm 0.6$ & $32.0 \pm 0.4$ \\
\hline HF5 & $36.0 \pm 0.4$ & $31.5 \pm 0.5$ \\
\hline HF6 & $35.8 \pm 0.5$ & $32.0 \pm 0.4$ \\
\hline HF7 & $33.9 \pm 0.5$ & $32.5 \pm 0.4$ \\
\hline HF8 & $35.4 \pm 0.5$ & $30.4 \pm 0.4$ \\
\hline HF9 & $35.3 \pm 0.5$ & $33.6 \pm 0.7$ \\
\hline HF10 & $36.3 \pm 0.6$ & $32.4 \pm 0.6$ \\
\hline HF11 & $35.2 \pm 0.5$ & $31.1 \pm 0.9$ \\
\hline HF12 & $35.1 \pm 0.5$ & \\
\hline
\end{tabular}

The engine efficiency using the different fuels are given in (Figure 4) For comparison purposes, efficiency curves for diesel and crude CNO are also included. There is a steady increase in efficiency as the load increases in all fuel systems. Fuels with higher values of GCVs did not necessarily produce the more efficient power generating systems. HF9 which has the composition 54\% CNO, $23 \%$ Ethanol and 23\% Butan-2-ol is found to be the most efficient blend. The Load- Efficiency curves for all the tested hybrid fuels lie generally close to diesel, hence it can be concluded that power production from the tested biofuels would not be much different from diesel.

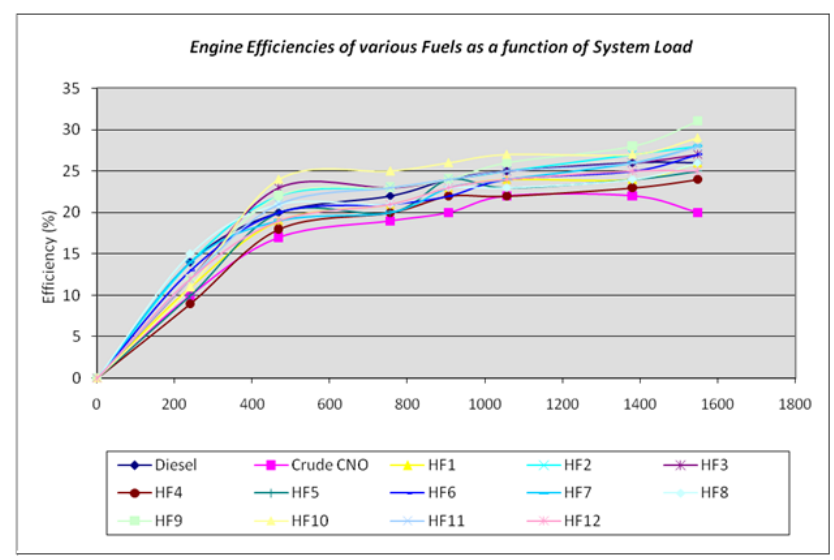

Figure 5. Effect on Load on Engine Efficiency for CNO / Ethanol / (Butan-1-ol / Butan-2-ol) Hybrid fuels

For sustainability the use of vegetable oil to exchange diesel includes a vary of potential environmental advantages. First, there is the decrease of emissions of toxic gases and particulate as compared to diesel, through the upper gas content of vegetable oil, though these advantages are not therefore evident once mistreatment straight edible fat in standard engines. Secondly, the employment of vegetable oil may be thought of $\mathrm{CO}_{2}$ neutral. The $\mathrm{CO}_{2}$ keep within the coconuts, husks and shells are used in the method of oil production (husk and shells for drying the copra) and burning of the oil. This $\mathrm{CO}_{2}$ is once more sequestrated throughout the growing of recent trees and nuts [11]. Other blessings of vegetable oil include:

- Lower emissions and toxic fumes than petroleum diesel fuel.

- Smoother running and reduced engine knock.

- Availability to the producer in remote area to run machinery and generate electricity once the roads are interrupt within the wet or costs are too high. 
Supporting a local industry that cuts down on fuel imports can profit fragile Pacific island countries well through enhancements in balance of payments and job creation. At the same time, coconut farmers are given access to a brand new, doubtless booming market because the distinction between the cost of their product and therefore the benchmark of the diesel price more widens. Even though there is substantial proof of the environmental advantages of mistreatment vegetable oil as a fuel, it is the native price of crude fuel that the $\$ 64000$ driver behind these developments within the Pacific island economies. Electrical utilities typically suffer from nice dependence on foreign diesel for power generation and are seeking new ways that to hedge these risks [11].

Future work on this area such as testing and characterising of different surfactants, fatigue load testing on diesel engines using different blends of biodiesel would ensure better understanding of the subject.

For biofuels to prosper in any nation, availability and affordability are the two primary requirements. Fiji's coconut industry is nowhere producing the capacity which would completely eliminate its dependency on imported oils. However, tax incentives to biofuel producers would generate sufficient interest to revive the coconut industry, and the potential use of coconuts as biofuels could stimulate coconut production provided there is proper awareness through the nation.

The high value of fossil fuels within the Pacific Island countries, and also the economic yet because the environmental hazard related to their use, build renewable energy significantly enticing within the region. New renewable energy comes additionally supply a chance to bring electrification to isolated island communities that antecedently lacked correct electricity provides. In copra oil, Pacific islands have a renewable fuel supply that's locally-produced, high-yielding, simple to method, and may be accommodated to a definite extent by existing diesel-based energy infrastructure. It is additionally environmentally friendly: not solely is that the burning of copra oil carbon neutral, however its production and distribution are often evaded important emissions, if the oil is ironed domestically using machinery operated by hand or powered using the oil itself. An extra advantage of copra oil within the Pacific Islands over different biofuels like vegetable oil is that enormous, under-utilised areas of coconut plantation exist already within the region, thus land use for copra oil production needn't vie with food production or variety. Though copra oil isn't accessible in spare quantities to utterly replace fuel use, potential exists for it to form a considerable contribution to some Pacific Island countries' energy desires [12].

Following the success of initial trials, the addition of tiny quantities of copra oil to diesel to be used in electricity generation is probably going to become widespread where the oil is out there at a competitive value.

However, realising the complete potential of copra oil as a fuel would require investment in oil process infrastructure, and in specialised generators capable of handling the oil in larger concentrations. Sadly, investment in renewable energy within the Pacific Ocean has traditionally been neglected as a result of an absence of awareness of the accessible choices, lack of institutional capability, and an absence of finance opportunities. Another revenant downside has been an absence of involvement and collaboration with native stakeholders, that was evident within the partial failure of the Fijian scheme represented .Further development of copra oil as an energy supply so needs higher cooperation between governments, international donors, coconut growers and millers, and local communities, with a stress on long-term capacity building instead of short-term infrastructure investment.

Another downside is that the volatility in costs of each copra oil and fossil-fuel alternatives, that makes the come back on any investment in biofuels unsure. Initially, overcoming this downside could need grant for copra oil production, in conjunction with the elimination of any existing subsidies that favour the employment of foreign fuel. Pacific Island governments square measure below very little pressure to support renewable energy on environmental grounds, since the region's per capita carbon emissions square measure already a mere quarter of the planet average. However, properly-implemented renewable energy schemes supply clear economic edges. A larger capability to use copra oil as another to diesel would buffer vulnerable Pacific Island countries against changes within the world value of each commodities, providing them with a much-needed live of economic stability and energy security. Additionally, the prospect of reducing carbon emissions through biofuel use provides foreign donors with an incentive to assist Pacific Island countries invest in property development of their energy resources.

Finally, Biodiesels is derived mainly from 'living carbon' rather than fossil carbon. For living carbon, as much carbon is absorbed from the atmosphere during its formation (in vegetable matter) as is released when it is burned. This makes biodiesel as a renewable and sustainable energy resource; a resource that is an integral part of the "Green Revolution Solution" to make the global environment cleaner and safer to live in.

\section{Conclusion}

It has been determined that tested biofuels produced engine efficiency and fuel economy similar to that of Diesel. The Hybrid fuel which constituted 23\% of each, ethanol and butan-2-ol was noted to be the most efficient.

\section{Acknowledgement}

The Author's would like to acknowledge Dr. Anirudh Singh and Mr. Viti Buadromo for setting up the experiment. Special recognition is also made to CIDA for the questions they answered and the literature works they provided for my research.

\section{Reference}

[1] Knother G, Dunn R O and Bagby M O, Bio-diesel: The Use of Vegetable Oils and Their Derivatives as Alternative Diesel Fuels, (online) National Centre for Agricultural Utilization Research, Agricultural Research Service, U.S. Department of Agriculture, Available from: http://www.biodiesel.org/resources/reportsdatabase/reports/gen/19 961201_gen-162.pdf [accessed 16.10.12]. 
[2] Cloin Jan, Copra oil as a biofuel; Challenges \& Opportunities. PPA conference paper; SOPAC; 2004. Available from: www.sopac.org/tiki/tiki-download_file.php?fileId=28 (accessed 19.10.12].

[3] Cloin J, Woodruff A and Furstenwerth D, Liquid Biofuel in Pacific Island Countries SOPAC Micellaneus Report 628; 2007.

[4] Singh PJ, Preparation, Characterisation and Engine Performance of Coconut Oil based Hybrid Fuels Master of Science Thesis (MSc), The University of the South Pacific; 2009.

[5] Raheman $\mathrm{H}$ and Phadatare AG, Diesel Engine Emissions And Performance From Blends of Karanja Methyl Ester and Diesel, Biomass and Bioenergy, Vol. 27, pp. 393-397; 2004.

[6] Pumwa J, The Investigation of Using Coconut Oil as a Possible Fuel Substitute for Diesel Engines, Department of Engineering, School of Engineering and Computer Science, Baylor University, Waco, USA; 2004.

[7] Chand V, Marketing Consultancy, Consultant Economist Rural Development, Soft Commodities and Renewable energy cogeneration using biomass, biogas and biofuels, Available from http://www.ruraldevelopment.info/Pages/FijiAgribusiness.aspx (accessed 20.10.12)

[8] Socio-economic and technical constraints and opportunities through experiences in Welagi and Lomaloma - Fiji Department of Energy; 17 November 2005.

[9] Agarwal D, Kumar L and Agarwal AV, Performance evaluation of a vegetable oil fuel Compression Ignition System, Renewable Energy; 33: 1147-1156; 2008.

[10] Demirbas A, Biodiesel Production Via SCF Method and Biodiesel Fuel Characteristics, Energy Conversion and Management, 47: 2271-2282; 2006

[11] Avialable from: http://www.naturalmatters.net/newsview.asp?news=686. (accessed 20.10.12).

[12] http://www.andrewgray.com/essays/coconutoil.htm. (accessed 21/10/12). 